\title{
СПОСОБ АНАЛИЗА УРОЖАЙНОСТИ ЛУГОВОЙ ТРАВЫ ОТ ВЫСОТЫ ПРОБНОЙ ПЛОЩАДКИ НАД УРЕЗОМ МАЛОЙ РЕКИ
}

Мазуркин П.М., Михайлова С.И.

ФГБОУ ВПО «Поволжский государственный технологический университет», 424000, г. Йошкар-Ола, Россия, e-mail: kaf_po@mail.ru

По патенту 2547763 выявляют волновые закономерности изменения относительной встречаемости видов в зависимости от высоты виртуальной пробной площадки над урезом воды путем статистического моделирования. Способ позволяет повысить точность учета наличия видов травяных и травянистых растений с учетом измерений нивелиром высоты расположения площадок без срезания травы.

Ключевые слова: трава, виды, пробная площадка, урез воды, влияние высоты

Изобретение [1] относится к анализу урожайности луговой травы, преимущественно на прирусловых пойменных лугах со сложным ветвлением малой реки на рукава и сложной поверхностью рельефа.

Сущность технического решения заключается в том, что водное питание растений происходит по разнице высот между урезом воды и пробной площадкой, причем самое короткое расстояние между ними - это створ измерений перпендикулярно линии уреза воды до центра пробной площадки по горизонтали. И это обстоятельство является доминирующим в обеспечении влагой от малой реки. Поэтому выделенный сложный по элементам фитоценоза участок малой реки принимается за единый объект для измерения по сырой массе срезанных проб травы, без их разделения по видовому составу.

Новизна заключается в том, что доказаны закономерности изменения высоты рельефа (без учета расстояний по створам измерения) от расстояния вдоль реки и высоты рельефа в зависимости от основного параметра прибрежного рельефа - высоты травы над урезом водной поверхности малой реки. Найден критерий, который не зависит от антропогенного влияния на разных участках пойменного луга.

Объект исследования - земельные участки на территории племенного завода «Азановский» Медведевского района Республики Марий Эл с растительным покровом в травяной пойме реки Манага (рис. 1).

\section{I}

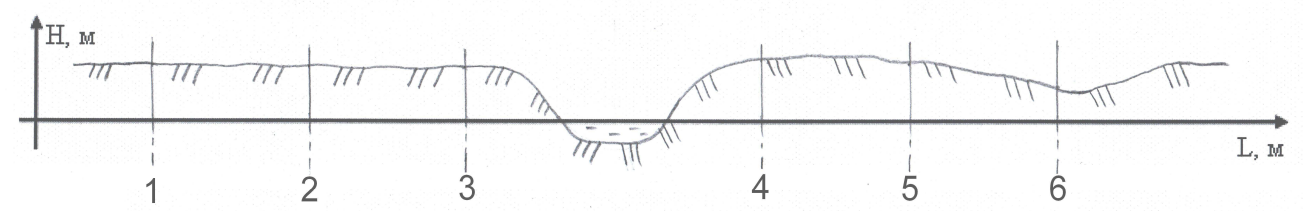

Рис. 1. Профиль первого створа выделенного участка малой реки

Предмет исследования - закономерности влияния расстояния поперек и вдоль реки, а также высоты от уреза воды на урожайность травяного покрова. 
Пробные площадки на правом берегу реки Ронга расположены на месте, где регулярно производился выпас скота. Территория имеет ярко выраженный рельеф (рис. 2) по двум сторонам рукавов и при этом имеются разные выдела пойменного луга с отличающимися антропогенными воздействиями.

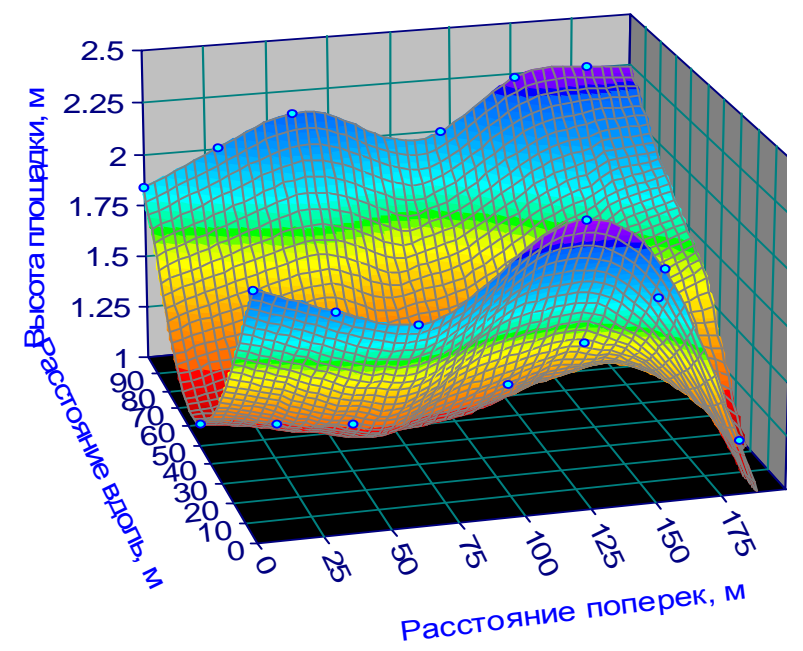

Рис. 2. Рельеф выделенного участка пойменного луга на реке Манага
Влияние высоты было выявлено статистическим моделированием в программной среде CurveExpert-1.40 (http://www.curveexpert.net) [2].

Каждый выдел имеет размеры: по длине реки 50 м, а по ширине - 30 м. Все выдела одинаковы по размеру и имеют площадь $1500 \mathrm{~m}^{2}$ или 15 ар (соток). Общая площадь участка равна $150 \times 210=31500 \mathrm{м}^{2}$ или 3,15 га. Общая продуктивность по сырой массе равна 208,8 ц или 20,88 т. А по сухому сену продуктивность равна 9390 кг (93,9 ц или 9,39 т).

Далее рассмотрим возможность закономерностей с волновыми составляющими. Мы придерживаемся концепции Декарта о необходимости применении алгебраического уравнения общего вида напрямую [3, 4].

После проведения испытаний проб травы и измерений высоты выявляют волновые закономерности изменения массы сырой пробы в зависимости от высоты пробной площадки над урезом воды малой реки по формуле

$$
m=\sum_{i=1}^{n} m_{i}, m_{i}=A_{i} \cos \left(\pi H / p_{i}-a_{8 i}\right), A_{i}=a_{1 i} H^{a_{2 i}} \exp \left(-a_{3 i} H^{a_{4 i}}\right), p_{i}=a_{5 i}+a_{6 i} H^{a_{7 i}},
$$

где $m$ - расчетная масса пробы сырой травы, г (рис. 3), $m_{i}$ - масса по составляющим уравнения, г, $H$ - высота центра пробной площадки над урезом водной поверхности малой реки в створе измерений по центру одной пробной площадки, м, $A_{i}$ - амплитуда (половина) колебания массы сырой травы, г, $p_{i}$ - полупериод колебания высоты над урезом воды, м, $a_{1} \ldots a_{8}$ - параметры уравнения, получаемые после идентификации по статистическим данным измерений массы сырой пробы травы, $i$ - номер составляющей общего уравнения, $n$ - количество детерминированных и волновых составляющих.

По формуле (1) с двумя фундаментальными физическими постоянными $e$ (число Непера или число времени) и $\pi$ (число Архимеда или число пространства) образуется изнутри изучаемого явления и/или процесса квантованный вейвлет-сигнал. 

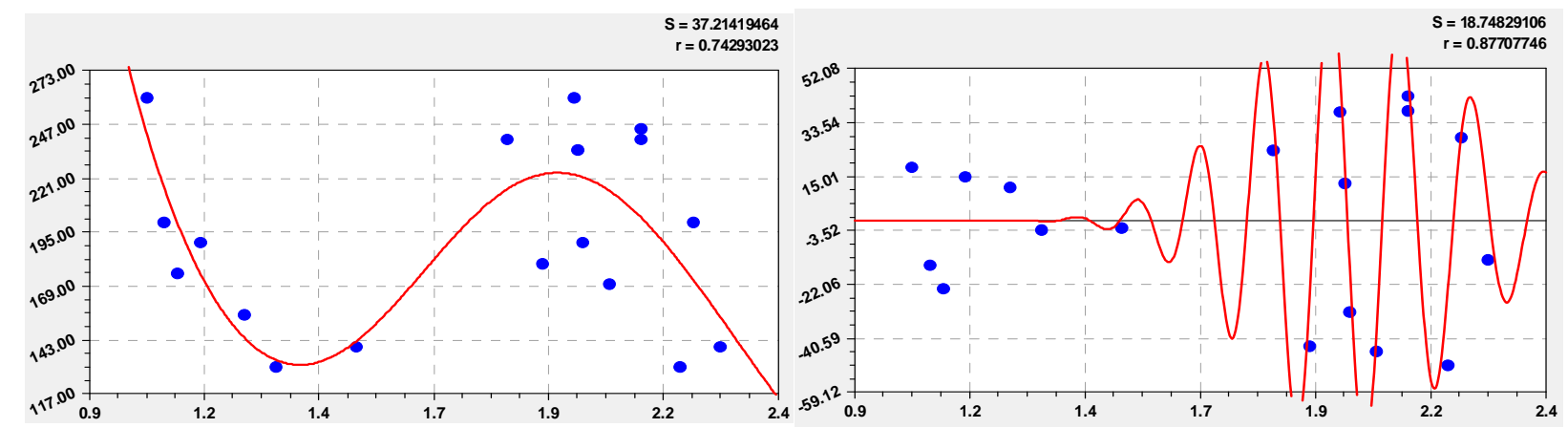

Тренд массы сырой пробы из двух законов

Первая волна возмущения сырой массы
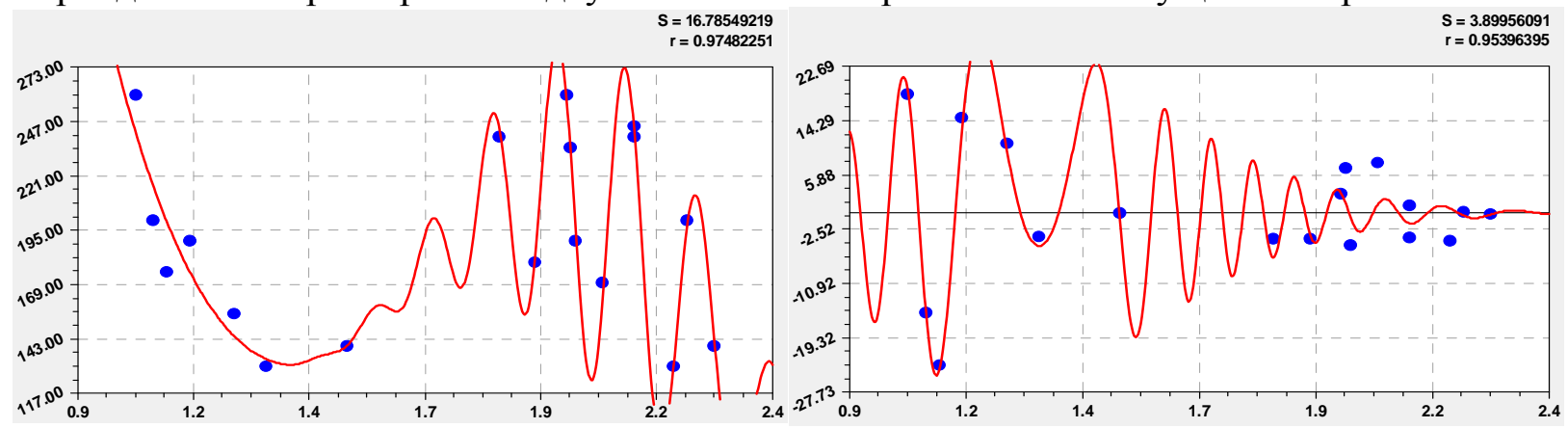

Совместная модель - тренд и одно колебание

Вторая волна возмущения сырой массы

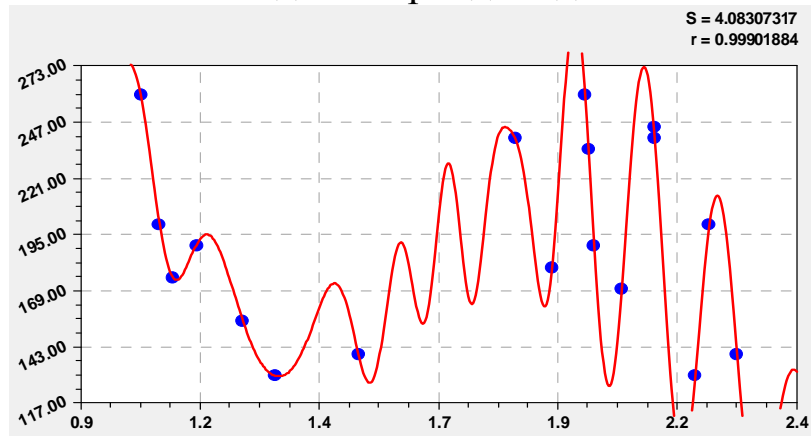

Общая модель - тренд и два колебания

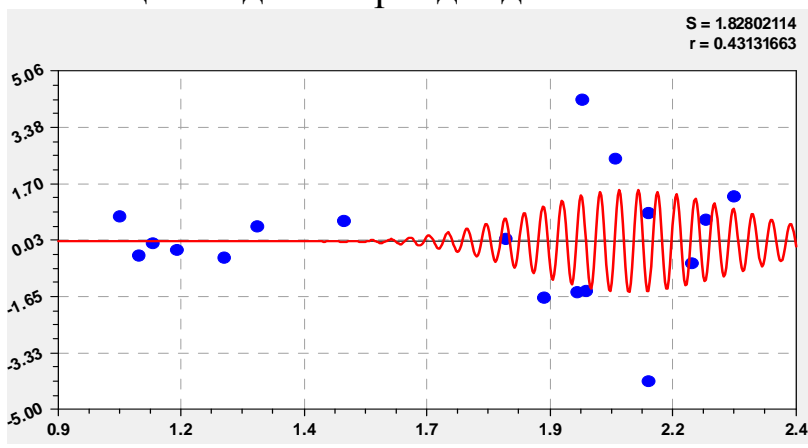

Дополнительное четвертое колебание

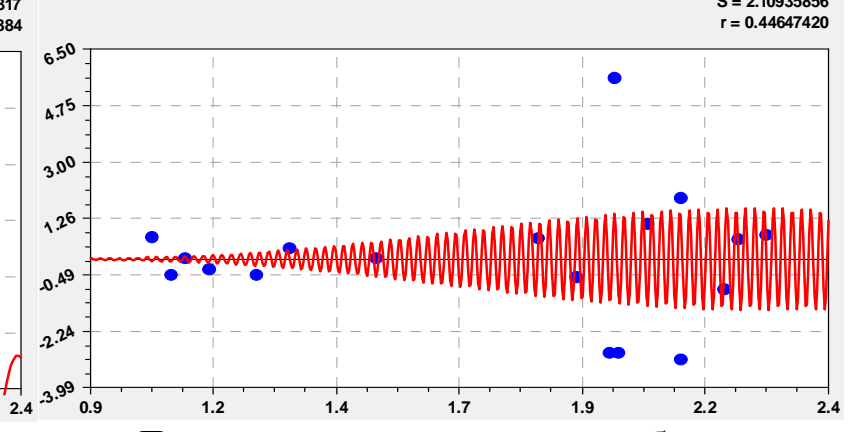

Дополнительное третье колебание

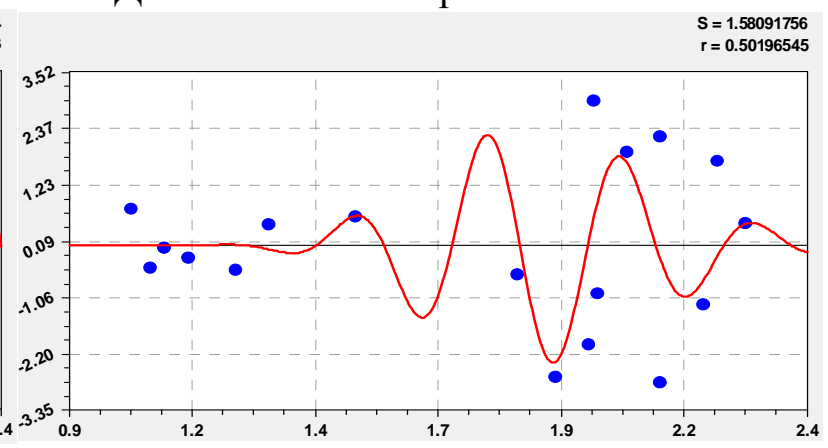

Рис. 3. Графики влияния высоты пробной площадки на массу пробы свежесрезанной травы

Параметры формулы (1) записываем в матричной форме в таблицу 1. Примечательно в ней доказательство волновой природы ландшафта.

Изобретение повышает функциональные возможности за счет ландшафтного измерения высоты над урезом воды, без привязки к расстояниям по створам и вдоль реки. Появляется возможность выделение делянок с равными высотами и на них проводить испытания для выявления других экологических факторов. 
Таблица 1 - Составляющие вейвлетов $y_{i}=a_{1 i} x^{a_{2 i}} \exp \left(-a_{3 i} x^{a_{4 i}}\right) \cos \left(\pi x /\left(a_{5 i}+a_{6 i} x^{a_{7 i}}\right)-a_{8 i}\right)$

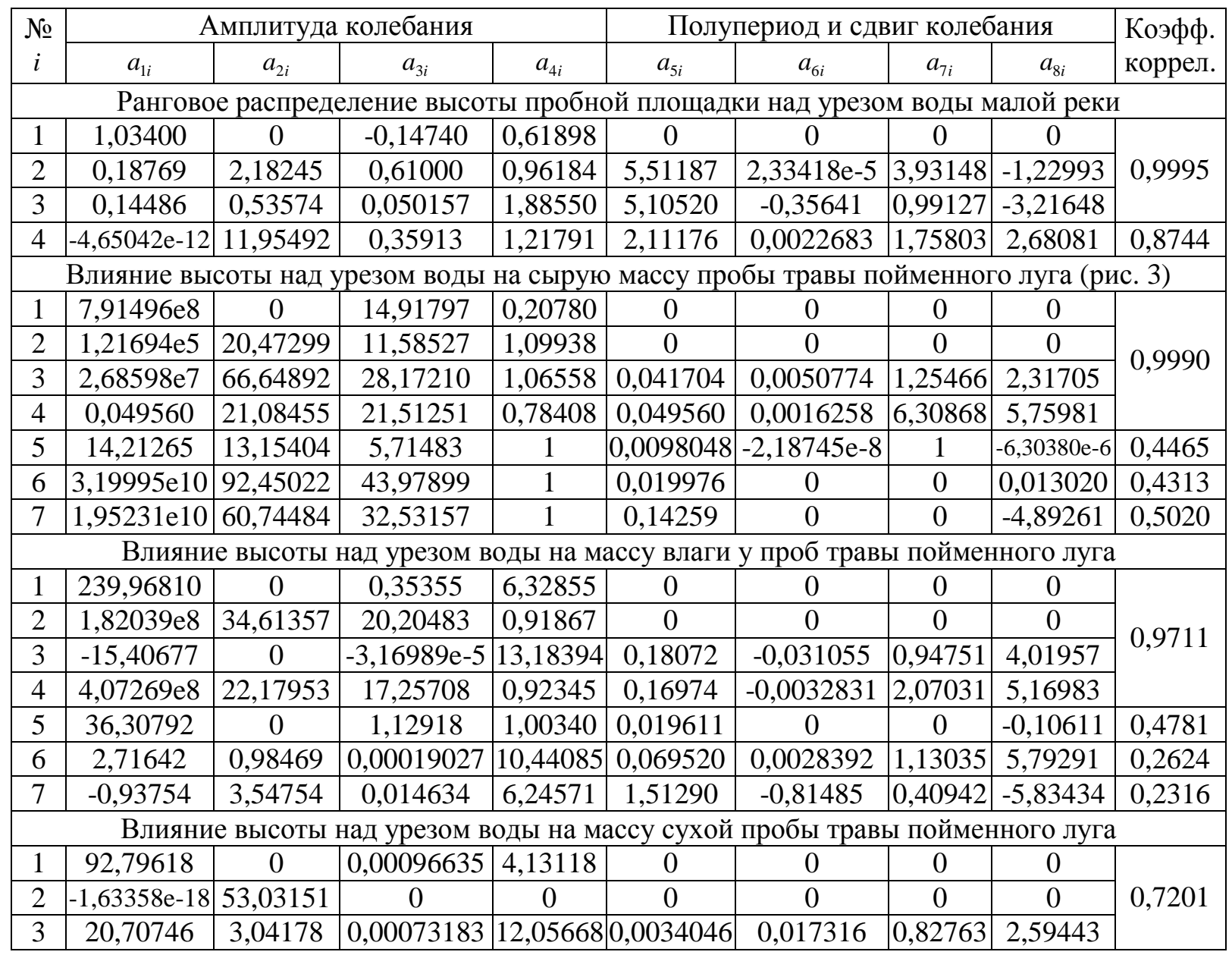

В таблице 2 даны оценки абсолютной $\varepsilon=\hat{y}-y$ и относительной $\Delta=100 \varepsilon / \hat{y}$ погрешности у моделей, параметры которых даны в таблице 1.

Таблица 2 - Оценка относительной погрешности моделирования

\begin{tabular}{|c|c|c|c|c|c|c|c|c|c|c|c|c|c|}
\hline \multicolumn{4}{|c|}{ Распределение высоты } & \multicolumn{10}{|c|}{ Влияние высоты пробы над поверхностью реки } \\
\hline \multirow{2}{*}{$\begin{array}{c}\text { Ранг } \\
R\end{array}$} & \multirow{2}{*}{$\hat{H}, \mathrm{M}$} & \multicolumn{2}{|c|}{ По модели } & \multirow{2}{*}{$H, \mathrm{M}$} & \multicolumn{3}{|c|}{ Сырая трава } & \multicolumn{3}{|c|}{ Сухая трава } & \multicolumn{3}{|c|}{ Масса влаги } \\
\hline & & $\mathcal{E}, \mathrm{M}$ & $\Delta, \%$ & & $\hat{m}, \Gamma$ & $\mathcal{\varepsilon}, \Gamma$ & $\Delta, \%$ & $\hat{m}_{c}, \mathrm{I}$ & $\mathcal{E}, \Gamma$ & $\Delta, \%$ & $\hat{m}_{6}, \Gamma$ & $\mathcal{E}, \Gamma$ & $\Delta, \%$ \\
\hline 0 & 1,03 & $-0,004$ & $-0,39$ & 2,14 & 245 & 2,50 & 1,02 & 90 & $-0,06$ & $-0,07$ & 155 & 6,36 & 4,10 \\
\hline 1 & 1,07 & $-0,003$ & $-0,28$ & 2,01 & 190 & $-1,91$ & $-1,01$ & 80 & $-16,70$ & $-20,87$ & 110 & $-10,24$ & $-9,31$ \\
\hline 2 & 1,10 & 0,001 & 0,10 & 1,92 & 180 & $-0,30$ & $-0,17$ & 70 & $-1,63$ & $-2,32$ & 110 & $-0,70$ & $-0,64$ \\
\hline 3 & 1,15 & $-0,013$ & $-1,15$ & 2,32 & 140 & 0,02 & 0,02 & 50 & $-0,53$ & $-1,07$ & 90 & $-2,37$ & $-2,63$ \\
\hline 4 & 1,25 & $-0,002$ & $-0,17$ & 2,07 & 170 & 0,21 & 0,12 & 65 & $-27,00$ & $-41,54$ & 105 & $-0,11$ & $-0,11$ \\
\hline 5 & 1,32 & $-0,001$ & $-0,11$ & 1,25 & 155 & $-0,50$ & $-0,32$ & 55 & $-8,41$ & $-15,29$ & 100 & $-0,61$ & $-0,61$ \\
\hline 6 & 1,5 & $-0,005$ & $-0,35$ & 1,10 & 175 & $-0,05$ & $-0,03$ & 70 & 2,07 & 2,96 & 105 & 4,16 & 3,96 \\
\hline 7 & 1,84 & 0,009 & 0,47 & 1,07 & 200 & $-0,43$ & $-0,22$ & 100 & 2,73 & 2,73 & 100 & $-3,65$ & $-3,65$ \\
\hline 8 & 1,92 & $-0,011$ & $-0,55$ & 1,03 & 260 & 0,75 & 0,29 & 110 & $-3,63$ & $-3,30$ & 150 & 2,42 & 1,62 \\
\hline 9 & 1,99 & $-0,004$ & $-0,22$ & 1,15 & 190 & $-0,25$ & $-0,13$ & 100 & 5,80 & 5,80 & 90 & $-2,94$ & $-3,26$ \\
\hline 10 & 2,00 & 0,006 & 0,32 & 1,32 & 130 & 0,52 & 0,40 & 90 & $-12,58$ & $-13,98$ & 40 & 1,95 & 4,89 \\
\hline 11 & 2,01 & $-0,006$ & $-0,28$ & 1,50 & 140 & 0,00 & 0,00 & 95 & 8,27 & 8,71 & 45 & $-0,76$ & $-1,69$ \\
\hline 12 & 2,07 & 0,008 & 0,38 & 1,84 & 240 & $-0,88$ & $-0,37$ & 100 & 10,67 & 10,67 & 140 & $-0,68$ & $-0,49$ \\
\hline 13 & 2,14 & $-0,003$ & $-0,13$ & 2,00 & 235 & 2,40 & 1,02 & 85 & $-11,77$ & $-13,85$ & 150 & 19,83 & 13,22 \\
\hline 13 & 2,14 & $-0,003$ & $-0,13$ & 2,14 & 240 & $-2,50$ & $\begin{array}{l}-1,04 \\
\end{array}$ & 100 & 9,94 & 9,94 & 140 & $-8,64$ & $-6,17$ \\
\hline 14 & 2,23 & 0,011 & 0,51 & 1,99 & 260 & $-2,10$ & $-0,81$ & 140 & 43,77 & 31,27 & 120 & $-10,62$ & $-8,85$ \\
\hline 15 & 2,26 & $-0,007$ & $-0,32$ & 2,23 & 130 & $-0,47$ & $-0,36$ & 80 & $-5,53$ & $-6,91$ & 50 & $-1,34$ & $-2,67$ \\
\hline 16 & 2,32 & 0,005 & 0,24 & 2,26 & 200 & 1,93 & 0,97 & 85 & 4,59 & 5,40 & 115 & 0,99 & 0,86 \\
\hline
\end{tabular}


Способ упрощается из-за того, что не требуется сушить пробы травы и это позволяет сразу же после срезки взвесить пробы на переносных весах и тут же эту пробу после взвешивания выбросить. Поэтому останется только один важнейший показатель - масса сырой пробы в зависимости от высоты пробой площадки ад урезом воды. Такое упрощение значительно расширяет возможности применения способа на гораздо большее количество пробных площадок, намечаемых вдоль реки на длинные участки малой реки. Но при этом требуется учесть и падение реки на этом участке малой реки.

\section{Литература}

1. Пат. 2547763 Российская Федерация, МПК А 01 G 7 / 00, А 01 G 23 / 00, G 01 С 5 / 00 (2006.01). Способ анализа видового состава луговой травы от высоты пробной площадки над урезом малой реки / Мазуркин П.М., Михайлова С.И., Ямбаева О.С.; опубл. 10.04.2015. Бюл. № 10.

http://www1.fips.ru/Archive/PAT/2015FULL/2015.04.10/DOC/RUNWC2/000/000/002/547/763/document.pdf

2. Мазуркин П.М., Михайлова С.И. Анализ видового состава луговой травы. Йошкар-Ола: ПГТУ, 2015. 156 с. ISBN 978-5-8158-1548-3

3. P.M. Mazurkin. Wavelet Analysis Statistical Data. Advances in Sciences and Humanities. Vol. 1, No. 2, 2015, pp. 30-44. doi: 10.11648/j.ash.20150102.11.

4. P.M. Mazurkin. Invariants of the Hilbert Transform for 23-Hilbert Problem, Advances in Sciences and Humanities. Vol. 1, No. 1, 2015, pp. 1-12. doi: 10.11648/j.ash.20150101.11.

\section{METHOD OF PRODUCTIVITY ANALYSIS MEADOW GRASS HEIGHT OF TEST SITE ON EDGE OF THE SMALL RIVER Mazurkin PM, Mikhailova SI \\ VPO "Volga State University of Technology" 424000, Yoshkar-Ola, Russia, e-mail: kaf_po@mail.ru}

By Pat 2547763 wave patterns of change in the relative occurrence of species are identified depending on the height of the virtual test site above the water edge by statistical modelling. EFFECT: method enables to improve the accuracy of accounting the presence of species of grass and herbaceous plants, taking into account the measurement with the level unit of height of location of the plots without cutting the grass.

Keywords: grass, species, the trial court, water edge, the height, of the impact

\section{References}

1. Pat. Russian Federation 2547763, IPC A 01 G 7/00, A 01 G 23/00, C 01 G 5/00 (2006.01). The method of analysis of the species composition of meadow grass on the height of the test platform's edge over the small river / Mazurkin PM, Mikhailova SI, Yambaeva OS ;; publ. 04/10/2015. Bull. Number 10.

http://www1.fips.ru/Archive/PAT/2015FULL/2015.04.10/DOC/RUNWC2/000/000/002/547/763/document.pdf

2. Mazurkin PM, SI Mikhailov An analysis of the species composition of meadow grass. Yoshkar-Ola: VSUT, 2015. 156 p. ISBN 978-5-8158-1548-3

3. P.M. Mazurkin. Wavelet Analysis Statistical Data. Advances in Sciences and $\mathrm{Hu}$ manities. Vol. 1, No. 2, 2015, pp. 30-44. doi: 10.11648/j.ash.20150102.11.

4. P.M. Mazurkin. Invariants of the Hilbert Transform for 23-Hilbert Problem, Advances in Sciences and Humanities. Vol. 1, No. 1, 2015, pp. 1-12. doi: 10.11648/j.ash.20150101.11. 